\title{
Temtamy syndrome
}

INSERM

\section{Source}

INSERM. (1999). Orphanet: an online rare disease and orphan drug data base. Temtamy syndrome. ORPHA:1777

Temtamy syndrome is a very rare congenital genetic neurological disorder characterized by agenesis/hypoplasia of corpus callosum with developmental abnormalities, ocular disorders, and variable craniofacial and skeletal abnormalities. 